\title{
Reframing from the ground up Redesigning a credit-bearing information literacy course using the Framework for Information Literacy for Higher Education
}

IB 1500 is a three-credit information - literacy course offered by the University Library at California State Polytechnic University, Pomona (Cal Poly-Pomona), which is taught by faculty librarians. The course was developed during the 2014-15 academic year and has been offered continuously since. While targeted primarily toward freshmen, in the course inevitably include a number of sophomores and upper-level students seeking to fulfill their lifelong learning General Education requirement, for which LIB 1500 is one of several options. While the development of LIB 1500 has been a labor of love, by the end of Spring Quarter 2017, those of us involved in teaching the class had noticed that the course was becoming dated and needed a complete overhaul. Therefore, during the 2017-18 academic year, librarians at Cal Poly-Pomona fundamentally redesigned LIB 1500 to reflect the threshold concepts described in the ACRL Framework for Information Literacy for Higher Education. In doing so, we learned valuable lessons about course structure, applied learning, and the iterative nature of course revision.

\section{Issues with the original course}

Prior to revising LIB 1500, the library faculty observed a disconnect between the theoretical concepts we discussed in class and the in-class activities that would follow. For example, a discussion of smart appliances might be followed up by a citation exercise or a discussion of online privacy by an activity involving use of reference sources on an unrelated topic. At times, it seemed as if the course had been created with two conflicting goals in mind, and the resolution to that conflict had been to attempt to do both things at the same time. The result was an in-class experience that was at best, eclectic, and at worst, incoherent.

In order to bring some sense of coherence to the class, we needed a structure that would allows us to organize the concepts we were teaching, yet be flexible enough to allow us to adjust for technological changes and the continuously updating nature of the information environment. As the threshold concepts outlined in the Framework for Information Literacy for Higher Education appeared to provide us with that balance of structure and flexibility around which we could rebuild our course, it seemed the logical choice to use the Framework as reworking the course.

\section{Planning the first revision}

In June 2017, an ad-hoc committee com-

Shonn M. Haren is library instruction coordinator at California State Polytechnic University in Pomona, California, email: smharen@cpp.edu

๑) 2019 Shonn M. Haren 
posed of five teaching librarians and our systems librarian set out to drastically overhaul and update LIB 1500. Our goals were ambitious. The structure of the course was to be shifted from a calendar week-based course to a modular course, with each module addressing one of the threshold concepts outlined in the Framework. Within each module, the individual lessons would each include a concept discussion and an in-class activity that related directly to each other, as well as relating in some way to the topic of the module that contained it. As illustrated students would be assigned a Wikipedia stub and expected to apply the skills and concepts learned in class to improve the stub by adding information, citations, and images.

As Cal Poly-Pomona embraces a "learn through doing" philosophy, we felt that this final provided our students with an opportunity to see how the concepts they were learning worked in a real world context, involving a resource that they all used at one time or another. Through a partnership with the Wikimedia Education Foundation, Wikipedia provided our course with a dash-

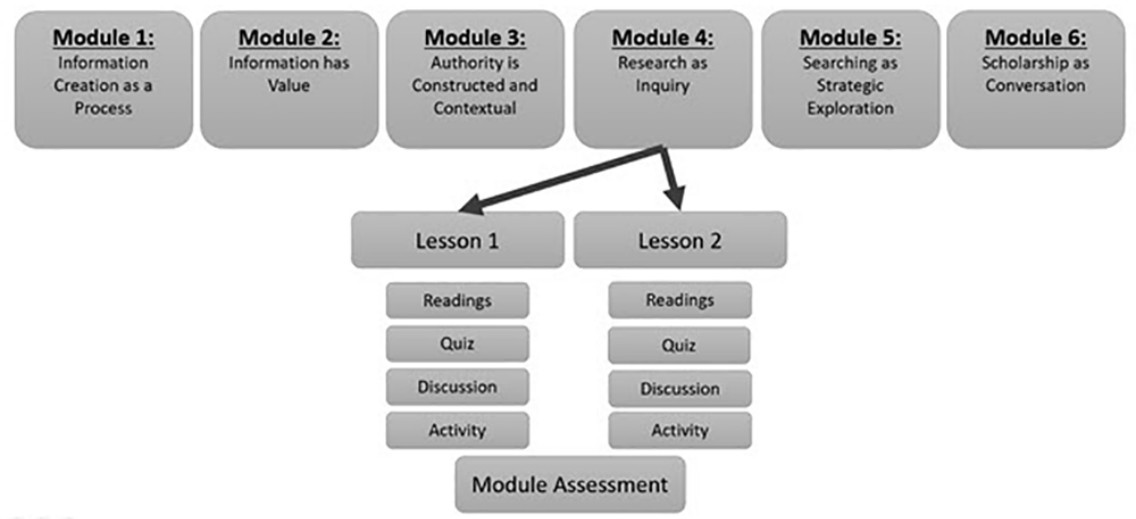

Figure 1: Correlation between the Framework and LIB 1500's modules.

in figure 1, we sought a direct correlation between each of our course modules and a concept explored in the Framework.

We also intended to replace the course final. The old course final had involved students picking a research topic at the beginning of the quarter and then performing a series of research activities about that topic, including searching for sources, citation of those sources, and source assessment. The final itself was a reflective essay in which the students would describe their experience with the research process. This was a solid assignment, but student engagement was low, and the whole process seemed a bit artificial. We wanted something that would demonstrate a more direct application of the skills they were learning in the class, and increase their engagement with the material. The revised final would be a group project in which the board, sandboxes, and training in how to edit Wikipedia and Wikipedia Standards.

In order to spread out the work, the librarians on the course revision committee each volunteered to write one of our course modules. They would be expected to produce the following:

- module learning outcomes that would map to the course learning outcomes,

- two-to-four unique lesson plans (depending on whether it was a one- or twoweek module) that included an internally coherent concept discussion and in-class activity and connected to the larger module theme,

- readings and reading quizzes for each lesson in the module,

- an end of module assessment that measured the student learning of the module learning outcomes. 
The overall goal was to provide the students with a coherent learning experience in each class, where their readings, lectures, applied activities, and major assignments all worked together to help them understand and apply the concepts they were learning.

\section{"Test driving" the new course}

The 2017-18 school year provided us with an opportunity to "test drive" the revised course. Over these three quarters, we offered four sections of LIB 1500 to a total of 90 students. During this period, we got a good idea of what worked and what still needed work. Restructuring LIB 1500 around the threshold concepts in the Framework was largely successful. Lessons felt much tighter and more coherent, and clearer connections between lessons and activities have also led to an increased degree of student engagement, as well as with the material in the classroom.

The Wikipedia final also proved to be one of the key strengths of the course revision. It was mentioned frequently in student surveys as one of their favorite parts of the class. The final has involved a high degree of student engagement, as students who might not have been greatly concerned about the formatting of a final paper suddenly became arch-perfectionists when told that the fruits of their labors would be visible on one of the most accessed websites on Earth. With very few exceptions, the products of group work on these projects has been excellent, even when students have been asked to work on a topic well outside their academic comfort zones, such as when a group composed of humanities and social science majors were asked to work on "Ice Jacking," a stub dealing with an engineering topic. We are particularly pleased with this project as it epitomizes the "learn by doing" ethos we embrace at $\mathrm{Cal}$ Poly-Pomona.

While the first iteration of our course revision had its share of successes, it also had a fair number of failures. For example, while the Wikipedia final has been popular among our students, we had difficulty integrating the training provided by Wikipedia into the course itself. This had to do in part with the fact that the trainings existed on a separate dashboard from our Blackboard course shell, and our initial uncertainty about how to incorporate the grading of these trainings. In this first iteration, completing the trainings provided 10 percent of the grade for the final, and was scored only at the end of the quarter when the final was due. While we could observe some correlation between the groups that completed the trainings and higher quality final projects, we didn't have a really good way to incorporate what they were being taught in the trainings with what we were teaching them in the classroom, and the disconnect was a problem.

Another challenge has involved Module 4, which addressed the Research as Inquiry frame. After teaching the original lessons for this module during Fall Quarter 2017, the librarians felt that these lesson plans didn't provide the students with enough hands-on experience in considering a research topic or doing background research on that topic. Therefore, in Winter Quarter 2018 we revised these lessons, focusing on a real world research problem, in this case selecting and doing background research on buying a car. In the first lesson, students would be broken up into groups and provided with a scenario (one example said they could buy any car they wanted, but it couldn't cost more than $\$ 10,000)$, and it then asked them to generate a mind map of what kind of topics they felt would be important to consider when looking for that vehicle.

In the second lesson, the students were provided with a variety of reference sources, such as the Kelly Blue Book, and asked, using those sources, to decide on a specific type of vehicle that met their earlier criteria and that they thought would be worth purchasing. This applied focus resulted in far greater student engagement and a better understanding of both the messiness and real world relevance of the research process.

Finally, contradictory though it may seem, structure also proved a problem in the first round of course revisions. Under the re- 
vised model, Module 5, which addressed the Search as Strategic Exploration frame, came near the end of the course, long after students should have begun searching for sources for their Wikipedia project. As a result, students had to begin to find sources for their final project long before they were introduced to useful tools and effective strategies for performing searches in catalogs, databases, or the open web. Our restructuring of the course had inadvertently forced our students to "go it alone" in one of the most crucial steps for preparing for their final.

\section{Conclusion}

A credit-bearing course is a complex mechanism with learning outcomes, lectures, readings, activities, and assignments all playing roles as moving parts that, when moving in concert, provide both the instructor and the student with an enjoyable, if sometimes challenging, experience. However, as harmony between those parts can be difficult to achieve, re- vising a course can be a daunting prospect.

In using the Framework for Information Literacy for Higher Education, we were able to build our course around its structure of general concepts and avoid some of the problems of discontinuity that had plagued us in the past. The Framework's structure allowed us to logically organize the concepts covered in our course while providing us with the flexibility to change things as new problems arose.

In light of the problems we identified in our first round of course revision, we chose, in the following academic year (2018-19) to add in-class Wikipedia training sessions, change where the research as inquiry and search as strategic exploration modules appeared in the class and add several new lessons to address concerns such as fake news. The flexibility and breadth provided by the Framework made these later revisions far simpler and less disruptive than they would have been in the older system. $\boldsymbol{n}$

("An open impediment," continues from page 204)

4. ACRL Research Planning and Review Committee, "2018 Top Trends in Academic Libraries: A Review of the Trends and Issues Affecting Academic Libraries in Higher Education," C $G R L$ News 79, no. 6 (2018): 286-300, doi:10.5860 /crln.79.6.286.

5. LeEtta Schmidt and Michael English, "Copyright Instruction in LIS Programs: Report of a Survey of Standards in the U.S.A.," The Journal of Academic Librarianship 41, no. 6 (2015): 736-43, doi:10.1016/j. acalib.2015.08.004.

6. Ibid.

7. John Eye, "Knowledge Level of Library Deans and Directors in Copyright Law," Journal of Librarianship and Scholarly Communication 2, no. 1 (2013): 1-14, doi:10.7710/2162-3309.1103.
8. Juan-Carlos Fernández-Molina, João Batista E. Moraes, and José Augusto C. Guimarães, "Academic Libraries and Copyright: Do Librarians Really Have the Required Knowledge?" College \& Research Libraries 78, no. 2 (2017): 241-59, doi:10.5860 /crl.78.2.16584.

9. "CC Wiki: Marking/Creators/Marking Third Party Content," Creative Commons, last modified November 19, 2003, 23:44, https://wiki.creativecommons.org/wiki /Marking/Creators/Marking_third_party _content\#Additional_explanation_and _tips.

10. https://sparcopen.org/our-work /sparc-library-oer-forum/, https:// creativecommons.org/2017/09/05/invitation -join-cc-open-education-platform/. z 